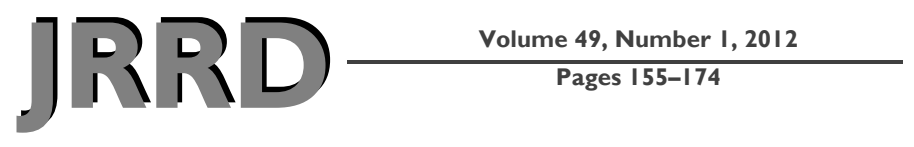

\section{Activity and participation after spinal cord injury: State-of-the-art report}

\author{
Philip M. Ullrich, PhD; ${ }^{1-2^{*}}$ Ann M. Spungen, EdD; ${ }^{3}$ Darryn Atkinson, PT; ${ }^{4}$ Charles H. Bombardier, PhD; ${ }^{2}$ Yuying \\ Chen, MD, PhD; ${ }^{5}$ Norma A. Erosa, MS; ${ }^{6}$ Shirley Groer, PhD; ${ }^{7}$ Lisa Ottomanelli, PhD; ${ }^{7}$ David S. Tulsky, PhD ${ }^{8}$ \\ ${ }^{1}$ Spinal Cord Injury and Disorders Services, Department of Veterans Affairs (VA) Puget Sound Healthcare System, Seat- \\ tle, WA; ${ }^{2}$ Department of Rehabilitation Medicine, University of Washington, Seattle, WA; ${ }^{3}$ VA Rehabilitation Research \\ and Development (RR\&D), Center of Excellence for the Medical Consequences of Spinal Cord Injury, James J. Peters \\ VA Medical Center, Bronx, NY; ${ }^{4}$ The Institute for Rehabilitation and Research Memorial Hermann, Houston, TX; \\ ${ }^{5}$ Department of Physical Medicine and Rehabilitation, University of Alabama at Birmingham, Birmingham, AL; ${ }^{6}$ Texas \\ A\&M University, Counseling Psychology, College Station, TX; ${ }^{7}$ VA Health Services Research and Development/RR\&D \\ Center of Excellence Maximizing Rehabilitation Outcomes, James A. Haley Veterans Hospital, Tampa, FL; ${ }^{8}$ Department \\ of Physical Medicine and Rehabilitation, University of Michigan, Ann Arbor, MI
}

\begin{abstract}
The importance of activities and community participation for persons with spinal cord injury (SCI) has been recognized for decades and yet theoretical and empirical advances have been limited. This report summarizes the recommendations for researchers on the topic of measuring activity and participation among persons with SCI formulated by the Spinal Cord Injury workgroup at the State-of-the-Art Conference on Outcome Measures in Rehabilitation held in January 2010. Activity and participation were defined as independent constructs ideally measured in reference to personal values and environmental influences. Measures of activity, participation, and factors influencing activity and participation are reviewed and critiqued. Gaps in available measures are described, measures in development are discussed, and suggestions for future research are made.
\end{abstract}

Key words: activity, disability, employment, functioning, measurement, outcomes, participation, quality of life, rehabilitation, spinal cord injury.
Abbreviations: $10 \mathrm{MWT}=10 \mathrm{~m}$ walk test; ADL = activity of daily living; ASSIST = Alcohol Smoking and Substance Involvement Screening Test; AUDIT = Alcohol Use Disorders Identification Test; BBS = Berg Balance Scale; BDI = Beck Depression Inventory; BMCA = brain motor control assessment; CAT = computerized adaptive testing; CCI = Charlson Comorbidity Index; CDE = common data element; CES-D = Centers for Epidemiologic Studies-Depression scale; CHART = Craig Handicap Assessment and Reporting Technique; $\mathrm{CHIEF}=$ Craig Hospital Inventory of Environmental Factors; CPI = Community Participation Indicators; DSM = Diagnostic and Statistical Manual of Mental Disorders; DSM-IV = DSM-Fourth Edition; EMG = electromyogram; FABS/M = Facilitators and Barriers Survey/Mobility; FIM = Functional Independence Measure; ICF = International Classification of Functioning, Disability, and Health; IPA = Impact on Participation and Autonomy; IRT = item response theory; ISNCSCI = International Standards for the Neurological Classification of Spinal Cord Injury; LIFE-H = Assessment of Life Habits; LiSat = Life Satisfaction Questionnaire; NIDRR = National Institute on Disability and Rehabilitation Research; NINDS = National Institute on Neurological Disorders and Stroke; NIH = National Institutes of Health; PARA-SCI = Physical Activity Recall Assessment for People with Spinal Cord Injury;

*Address all correspondence to Philip M. Ullrich, PhD; SCI/D Services, 128NAT, 1660 S. Columbian Way, Seattle, WA 98108. Email: philip.ullrich@va.gov

http://dx.doi.org/10.1682/JRRD.2010.06.0108 
Abbreviations: (cont.) PARTS/M = Participation Survey/ Mobility; PHQ-9 = Patient Health Questionnaire-9; PRO = patient-rated outcome; PROMIS = Patient- Reported Outcomes Measurement Information System; QOL = quality of life; RR\&D = Rehabilitation Research and Development; SCI = spinal cord injury; SCI/D = spinal cord injuries and disorders; SCIFAI = spinal cord injury Functional Ambulation Inventory; SCIM = Spinal Cord Independence Measure; SCSC = Spinal Cord Injury and Disorders system of care; SOTA = State-of-theArt; VA = Department of Veterans Affairs; WHO = World Health Organization; WISCI-II = Walking Index for Spinal Cord Injury-II; WST = Wheelchair Skills Test; WWII = World War II.

\section{INTRODUCTION}

Prior to World War II (WWII), persons who sustained a spinal cord injury (SCI) could expect to survive only weeks, and even if the odds of survival had been in their favor, no rehabilitative care was available that would have allowed them to pursue ordinary life aims [1]. Owing to advances in emergency medicine, antibiotics, and other aspects of acute medical care, thousands of veterans who sustained an SCI in the conflicts of WWII were able to return home. The survival of these individuals prompted the Department of Veterans Affairs (VA) to develop the first specialized care centers dedicated to SCI in the United States, broadening the aims of care for persons with disabilities to include comprehensive restoration of their functional potential in physical, social, vocational, emotional, and recreational areas of life [2]. By the closing years of WWII, three dedicated SCI care centers were opened by the VA. Today, the VA Spinal Cord Injury and Disorders system of care (SCSC) has expanded to 24 SCI care centers that administer specialized care to approximately 17,000 veterans with spinal cord injuries and disorders (SCI/D), making the VA the largest single provider of SCI/D care in the world [3]. In contemporary times, the lifespan of a veteran with SCI/D can be measured in decades. As a result, the attention of clinicians, researchers, and veterans with SCI/D is increasingly turned toward understanding and optimizing psychosocial functioning, such as activity levels and community participation.

Veterans with SCI/D comprise a distinct population deserving additional attention in research and clinical settings for several reasons. The average age of veterans with SCI/D is 55 years, approximately 18 years older than that of their counterparts in the SCI Model Systems. Little is understood about outcomes among older persons with SCI/D. Nearly half of all veterans with SCI/D served by the VA have injuries of nontraumatic etiology; little empirical literature characterizes the psychosocial concerns of persons with nontraumatic SCI/D. Veterans also tend to have lower socioeconomic status and more comorbid medical conditions than the general population, suggesting they may be at increased risk for lower levels of functioning.

As lifespans lengthen among veterans with SCI/D, there is increasing awareness of issues related to aging with SCI/D and a growing need to focus resources on understanding how to assess and address lapses in activity levels and community participation in this population. VA SCSC is extensive and comprehensive and has been in development for more than 65 years, and yet, there is only a limited body of empirical knowledge about veterans with SCI/D that could inform care providers or veterans about important outcomes. Most of what we know about SCI/D comes from research that does not involve veterans, and little of that research has involved populations that are even comparable to veterans on demographic and medical factors (e.g., older age, nontraumatic injuries). As just noted, veterans with SCI/D are different from other populations in important ways, and whether research involving nonveterans with SCI/D will generalize is unknown.

A clear need exists for empirical research aimed at gaining a better understanding of activities, participation, and other outcomes among veterans with SCI/D. Future research among veterans with SCI/D could benefit from a synthesis of expert opinion on the measurement of activities and participation and recommendations for research. Against this general background, this report describes findings of the SCI Workgroup from the State-of-the-Art (SOTA) Conference on Outcome Measures in Rehabilitation, sponsored by the VA Rehabilitation Research and Development (RR\&D) Service.

\section{SPINAL CORD INJURY WORKGROUP METHODS}

A group of researchers and clinicians in the field of SCI rehabilitation was selected by the SOTA organizers and invited to participate in a 2-day workgroup. Participants were selected based on their expertise in SCI 
research and clinical care and to represent numerous SCI rehabilitation disciplines and diverse VA and SCI Model Systems sites. A diverse panel of participants was selected so that recommendations for instruments and research would be prepared with real-world use and implementation in mind. Workgroup participants were given the charge to draw upon their knowledge base and expert opinion to formulate recommendations for researchers on the topic of measuring activity and participation outcomes among persons with SCI. To formulate recommendations, the workgroup held evaluative discussions of instruments that are currently being used or developed to measure outcomes after SCI. Measures were evaluated according to the volume and quality of published empirical support for measures and workgroup members' opinions on the practical utility of measures in clinical settings. During and after the SOTA meeting, several of the committee members performed limited literature reviews to supplement the results of the workgroup discussions and to better place workgroup recommendations within the context of past empirical and theoretical work. Importantly, the objective of the SOTA was not to conduct a comprehensive review of the research literature on these topics. Rather, the aim was to develop and share commentary and recommendations from the standpoint of expert opinion. Workgroup members held two telephone conferences subsequent to the SOTA to review and refine findings.

\section{OVERVIEW OF RECENT LITERATURE ON ACTIVITY AND PARTICIPATION AFTER SPINAL CORD INJURY}

In the last decade, interest has surged in the conceptualization and measurement of activity and participation among rehabilitation populations. The timing of this SOTA was fortuitous because participants were able to refer to recent empirical publications and consensus statements when formulating final recommendations. What follows is an overview of recently published reports germane to the measurement of activity, participation, and similar constructs among persons with SCI.

In November 2001, a National Institute on Disability and Rehabilitation Research (NIDRR)-funded conference convened to discuss the state of the science of measuring quality of life (QOL) in rehabilitation medicine [4-5]. QOL was described as the emphasis of an out- comes model for evaluating rehabilitation care in the resulting series of articles [6]. Tate et al. reviewed the literature on QOL after SCI [7]. They noted that popular measures of QOL have limited utility among persons with SCI because of inappropriate questions for persons with locomotor disabilities and insensitivity to personal values or interpretations of QOL. Similar concerns were reviewed in depth by Hays et al. in the same series [8] and by other investigators in more recent years [9-10]. With those limitations in mind, past research has shown that persons with SCI evidence lower QOL than persons without SCI and that their QOL may decline with age. QOL among persons with SCI has consistently been associated with various conceptualizations of participation, such as involvement in the community, employment, marriage, and social support [11]. QOL has not shown consistent or strong associations with biomedical factors such as etiology or severity of injury [11].

In 2007, NIDRR supported a symposium to clarify the state of knowledge about postacute rehabilitation outcomes, identify research challenges, and promote research [12]. In a publication reporting from the symposium, Clohan et al. noted that activity and participation measures are inadequately developed, especially in areas such as emotional well-being, vocational involvement, and family systems [13]. Duncan and Velozo suggested the use of item response theory (IRT) and computerized adaptive testing (CAT) to develop measures of rehabilitation outcomes [14]. The symposium recommended that SCI researchers (1) develop cognitive and psychosocial outcome measures that are low in respondent burden and valid across populations using IRT and CAT; (2) develop participation, activity, and social support measures; (3) evaluate reliability and validity of measures; and (4) assess environmental factors to allow adjustment of outcomes.

In 2008, NIDRR sponsored a broad review of outcome measures in SCI research, including a participation workgroup [15]. The workgroup reviewed the empirical literature to identify participation measures appropriate for use among persons with SCI. Three measures met criteria of having been used with people with SCI, cited in literature between 2000 and 2007, and used by two or more research groups. The three measures that met these criteria were the Craig Handicap Assessment and Reporting Technique (CHART) [16], the Assessment of Life Habits (LIFE-H) [17], and the Impact on Participation and Autonomy (IPA) questionnaire [18] (Table 1). However, the authors noted that existing measures are inadequate for 
Table 1.

Social and emotional measures.

\begin{tabular}{|c|c|c|c|c|}
\hline Domain/Measure & Acronym & Description & Limitations & Population \\
\hline \multicolumn{5}{|l|}{ Social } \\
\hline $\begin{array}{l}\text { Craig Handicap } \\
\text { Assessment and } \\
\text { Reporting Technique }\end{array}$ & CHART & $\begin{array}{l}\text { 32-item questionnaire scored in } \\
\text { domains physical independence, } \\
\text { cognitive independence, mobility, } \\
\text { occupation, social integration, and } \\
\text { economic self-sufficiency. }\end{array}$ & $\begin{array}{l}\text { Excludes subjective } \\
\text { appraisals. Ceiling } \\
\text { effects. }\end{array}$ & SCI \\
\hline $\begin{array}{l}\text { Impact on Participation } \\
\text { and Autonomy }\end{array}$ & IPA & $\begin{array}{l}\text { 32-item questionnaire assessing } \\
\text { participation and restrictions. Subscales } \\
\text { include social relations, self-care, } \\
\text { mobility, leisure, family role, } \\
\text { work, and education. }\end{array}$ & $\begin{array}{l}\text { Floor and ceiling } \\
\text { effects. Smaller evi- } \\
\text { dence base. }\end{array}$ & $\begin{array}{l}\text { Persons with } \\
\text { disability }\end{array}$ \\
\hline $\begin{array}{c}\text { Life Satisfaction } \\
\text { Questionnaire }\end{array}$ & LiSat & $\begin{array}{l}\text { 9-item measure of life satisfaction } \\
\text { in domains global, vocational, financial, } \\
\text { leisure, friends, sexual, activities of daily } \\
\text { living, family life, and partnership. }\end{array}$ & Limited SCI research. & Any \\
\hline
\end{tabular}

\begin{tabular}{|c|c|c|c|c|}
\hline Emotional & & & & \\
\hline $\begin{array}{l}\text { Beck Depression } \\
\text { Inventory }\end{array}$ & BDI & $\begin{array}{l}\text { 21-item measure of depressive } \\
\text { symptoms. }\end{array}$ & $\begin{array}{l}\text { Lengthy and does not } \\
\text { match DSM-IV criteria. }\end{array}$ & Any \\
\hline $\begin{array}{l}\text { Centers for } \\
\text { Epidemiologic Studies- } \\
\text { Depression }\end{array}$ & CES-D & $\begin{array}{l}\text { 20-item measure of depressive } \\
\text { symptoms. }\end{array}$ & $\begin{array}{l}\text { Lengthy and does not } \\
\text { match DSM-IV criteria. }\end{array}$ & Any \\
\hline $\begin{array}{l}\text { WHO Alcohol, Smoking } \\
\text { and Substance Involvement } \\
\text { Screening Test }\end{array}$ & $\begin{array}{l}\text { WHO } \\
\text { ASSIST }\end{array}$ & $\begin{array}{l}\text { 8-item measure screening for } \\
\text { lifetime and current other drug use, } \\
\text { dependence, and impairment. }\end{array}$ & - & Any \\
\hline $\begin{array}{l}\text { Patient Health } \\
\text { Questionnaire-9 }\end{array}$ & PHQ-9 & $\begin{array}{l}\text { 9-item measure matching DSM-IV } \\
\text { criteria for major depression. }\end{array}$ & $\begin{array}{l}\text { Somatic symptoms } \\
\text { overlap with SCI } \\
\text { issues. }\end{array}$ & Any \\
\hline $\begin{array}{l}\text { Alcohol Use Disorders } \\
\text { Identification Test }\end{array}$ & AUDIT & $\begin{array}{l}\text { 10-item measure of alcohol misuse, } \\
\text { symptoms of dependence. }\end{array}$ & - & Any \\
\hline
\end{tabular}

addressing the person-environment interaction inherent to participation and that some measures give no consideration to personal values. They recommended that future measures address these conceptual limitations and be developed utilizing modern measurement techniques.

Noonan et al. compared the psychometric performance of three measures of participation and found ceiling effects for each measure [19]. Otherwise, psychometric performance was adequate for all measures. Post et al. reviewed measures of participation that have been utilized among persons with SCI in published research [20]. Measures were reviewed for psychometric evidence and coverage of the International Classification of Functioning, Disability, and Health (ICF) [21] domains of activity and participation, with the Life Satisfaction Questionnaire (LiSat) [22] being recommended as the superior tool (Table 1).

The above efforts are complimentary on a number of points. First, each considers activity and participation critical outcomes among persons with SCI. Furthermore, appropriate measures for persons with SCI are lacking, primarily because of measures containing content that is 
a poor fit for someone who does not mobilize by walking or a lack of empirical study of the measures among persons with SCI. Those measures that have been utilized among persons with SCI often show limitations such as ceiling effects or weak and inconsistent associations with other relevant constructs. Finally, activity and participation are highly individualized constructs and it may be necessary to assess or account for influential environmental factors. In fact, participation is defined by interaction with environmental factors in some quarters.

Clearly, activity and participation are important but conceptually complex constructs, and this could well account for inadequacies in empirical research in this area. Whiteneck and Dijkers recently described conceptual and methodological issues with the construct of participation and environmental factors that interact with impairment [23]. The authors note that participation and environmental factors that interact with impairment are inadequately conceptualized in the ICF [21] and that lack of theoretical clarity impedes successful measurement. Whereas the ICF suggests multiple methods for classifying activity and participation, the authors take the stance that participation and activity should be conceptualized and measured as distinct constructs. The authors suggest a number of conceptual distinctions between activity and participation. Activity is considered action by an individual that can be assessed as a characteristic of a person. Participation may involve numerous activities that occur with or for others to fulfill societal roles. Participation is assessed at the level of person and environment.

SCI workgroup recommendations were informed by the theoretical and empirical efforts just reviewed. In the interest of formulating recommendations for research on activity and participation among veterans with SCI, the SCI workgroup adopted the following objectives:

1. Define constructs of activity and participation after SCI.

2. Recommend measures of activity and participation after SCI.

3. Describe gaps in available measures of activity and participation after SCI.

4. Identify factors that influence activity and participation after SCI.

5. Recommend measures of factors that influence activity and participation after SCI.

6. Describe gaps in measures of factors that influence activity and participation after SCI.

7. Recommend directions for future research.

\section{CONCEPTUALIZING AND MEASURING ACTIV- ITY AND PARTICIPATION AFTER SPINAL CORD INJURY}

For the purposes of this SOTA, "activity” was understood to refer to the broad class of behavioral, cognitive, and emotional experiences of individuals. "Participation," by contrast, was considered to refer to persons' interactions with their social environment. The drawing of this conceptual distinction between activity and participation is considered one option for utilization of ICF classifications [21] and is consistent with other expressed theoretical positions [23]. The workgroup also considered the measurement of factors that influence activity and participation to be critical in discussions of activity and participation measurement. After all, physical barriers, attitudinal bias, mental health problems, and medical problems can influence what a person with mobility impairments is able to do. These considerations are especially relevant to veterans with SCI/D because past research has suggested that the general veteran population may be more at risk for medical problems and psychosocial dysfunction than nonveterans [24-26]. With the aim of inclusively identifying factors with potential influence on activity and participation, the workgroup organized influential factors within social, emotional, physical, medical, and environmental domains.

\section{EXISTING MEASURES OF ACTIVITY, PARTICI- PATION, AND INFLUENTIAL FACTORS}

\section{Activity Measures}

Available activity measures are diverse, ranging from reports of activities of daily living (ADLs) to objective measures of motor activity (Table 2). In the next sections, ADL and motor activity measures are discussed separately.

\section{Activities of Daily Living Measures}

The Physical Activity Recall Assessment for People with Spinal Cord Injury (PARA-SCI) was developed specifically for persons with SCI in order to objectively measure the type, frequency, duration, and intensity of specific physical activities [27]. The PARA-SCI is an interview tool organized around recall of activities undertaken during the 3 previous days, yielding scores for cumulative activity, leisure-time activity, and lifestyle 
Table 2.

Physical measures.

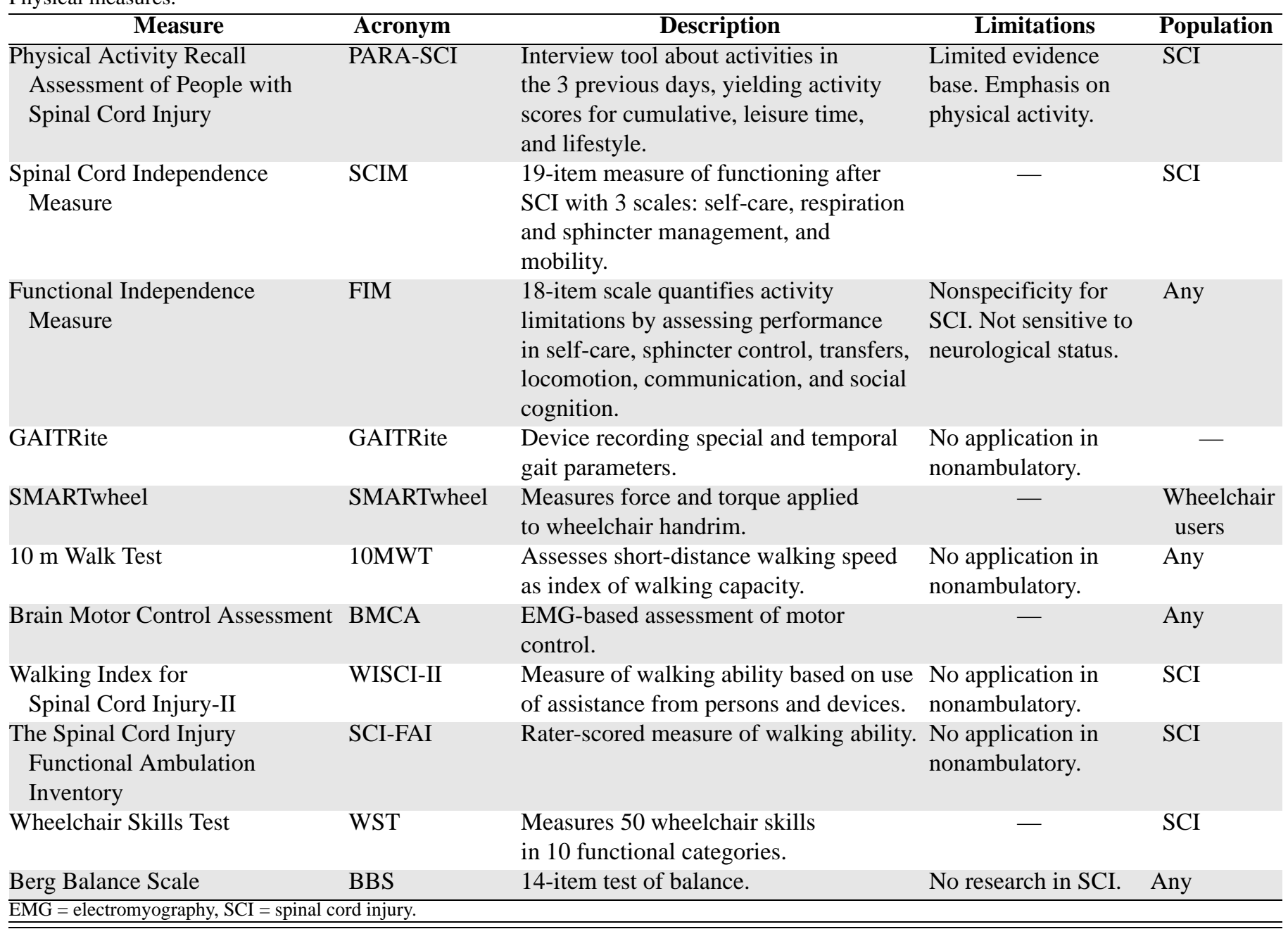

activity. The reliability and validity of the tool have been demonstrated by the developers in recent years [27-29]. Limitations of the PARA-SCI include limited use by investigators beyond the developers, emphasis on physical activity, exclusion of subjective appraisals, and the technical complexity of interview administration.

The Spinal Cord Independence Measure (SCIM) is a disability scale developed for patients with SCI [30]. The SCIM measures the following areas of function: selfcare, respiration and sphincter management, and mobility. Each area is scored according to its proportional weight in general activity. The final score ranges from 0 to 100 and rates functional achievements according to their importance [30]. The SCIM shows high interrater reliability and has been found to be more sensitive to changes in function than the Functional Independence
Measure (FIM) [30]. In the SCIM II, some SCIM items were rephrased to improve reliability of the scale [31]. A third version of the SCIM (SCIM III), made up of three subscales, was formulated following comments by experts from several countries and Rasch analysis performed on the SCIM II. The results supported the compatibility of the SCIM subscales with the stringent Rasch requirements. The scores of each SCIM III subscale appear to be reliable and useful quantitative representations of specific constructs of independence after SCI. The results also suggest that there is merit in further refining the scale [32].

The FIM is probably the most widely used functional assessment measure in clinical rehabilitation and research [33]. This 18-item scale quantifies activity limitation by assessing performance in self-care, sphincter 
control, transfers, locomotion, communication, and social cognition on a 7-point ordinal scale ( $1=$ complete dependence, $7=$ complete independence). If the points for each item are added, the possible total FIM score ranges from 18 to 126.

The psychometric properties of the FIM have been studied extensively and shown to be reliable [34]. In a Rasch analysis of the FIM, two separate domains were defined: motor and cognitive [35]. Research has shown that the cognitive domain is not informative for persons with SCI because of a substantial ceiling effect and limited sensitivity to change over time [36]. Other limitations of the FIM include (1) nonspecificity for SCI; (2) inability to detect subtle, but important, difference in functional levels between paraplegia and tetraplegia [37]; and (3) less applicability to outpatient rehabilitation settings.

\section{Motor Activity Measures}

A number of objective measures of motor activity and mobility are available. The GAITRite system (CIR Systems, Inc; Havertown, Pennsylvania) was designed to be a simple tool for use in clinical and research settings for assessment of gait. This device is able to record spatial and temporal gait parameters as a person walks over an electronic walkway. Three-dimensional motion capture systems have been used to demonstrate validity and test-retest reliability [38-39]. These outcome measures can be used to quantitatively assess changes in a person's gait due to an intervention such as robotic locomotor therapy and resistance training in SCI.

The SMARTwheel was developed as a method for measuring the force and torque applied to the handrim of a wheelchair [40]. The measure is considered to be informative for optimizing propulsion techniques and selecting wheelchairs [41-42].

The $10 \mathrm{~m}$ walk test (10MWT) was initially developed to assess short-distance walking speed [43-45]. The 10MWT is a validated, reliable measure for assessing walking function and capacity in individuals with SCI [45-46]. The 10MWT is responsive to initial rehabilitation and ongoing improvement in locomotor capacity in those with incomplete SCI [47]. A limitation to the 10MWT is that its reliability can be influenced by a patient's poor walking function that may be due to reasons other than walking ability [48].

The brain motor control assessment (BMCA) provides a quantitative method to characterize motor control in persons with neurological disorders. This is done by using multichannel surface electromyogram (EMG) recordings and protocols to evaluate control of neck, shoulder, trunk, upper-limb, and lower-limb muscles in the supine position. These recording are compared with patterns recorded from neurologically intact control subjects. BMCA has been used to demonstrate the ability to modify EMG reflex excitability in many persons clinically classified as complete SCI [49]. Applications include documentation of treatment effects for returning motor control [50], assessment of spasticity and cocontraction [51], and provision of objective criteria for the selection of intervention strategies [52].

The Walking Index for Spinal Cord Injury-II (WISCIII) was created to measure ability to walk after an SCI. It is a validated and reliable ranking tool for use in SCI population clinical trials. The assessment index is completed by ranking a person's ability to walk on a scale from 0 (most impairment) to 20 (least impairment). The ranking is based on an individual's use of physical assistance from one or more persons, braces, and other devices. The WISCI-II ranking is based only on the severity of impairment and cannot be used as an indicator of functional independence [53-54]. A study found that the WISCI-II is sensitive to recovery of walking ability [55].

The Spinal Cord Injury Functional Ambulation Inventory (SCI-FAI) is a rater-scored measure of walking ability in persons with SCI [56]. The SCI-FAI has moderate to good interrater and intrarater reliability. SCI-FAI scores showed a 45 percent improvement after a training program. Overall, this assessment tool appears to be good for persons who can ambulate, but has no application for non-weight-bearing individuals with little to no walking ability [56].

The Berg Balance Scale (BBS) is a validated and reliable 14-item scale initially developed to measure balance in the elderly [57-58]. Another validated use of the BBS is predicting falls within the elderly population [59]. The materials needed to complete the test include two chairs (one with arms and one without), a ruler, a 6-inch step, and a stopwatch. The measure is primarily used in the clinical setting and takes 15 to 20 minutes to administer [60]. The BBS has recently been studied for use as a balance tool [61] in the SCI population. A limitation of the BBS is that is has not been validated for use in individuals with SCI at this time.

Assistive technology for mobility, including wheelchairs, plays an important role in community participation among persons with SCI. For example, a recent 
study found that individuals with SCI perceived wheelchairs as the most significant factor limiting participation, beyond the impact of neurological impairment [62]. Wheelchair-related mobility can be measured by several methods, including direct observation and recording of distance and speed, activity questionnaires, heart rate monitoring, and calorimetry for estimating energy expenditure [63]. A number of factors can be associated with level of wheelchair mobility. Among them, wheelchair skills are currently under investigation by the SCI Model Systems researchers. The Wheelchair Skills Test (WST) is a measure that objectively evaluates wheelchair skills required for daily functioning. The WST version 2.4 measures 50 skills in 10 areas that are scored on a 2-point scale ( 0 = fail, $1=$ pass) to produce four summary scores: total score, total percentage, left/right asymmetry ratio, and goal attainment score. This instrument has been tested among persons with SCI, showing acceptable reliability and validity [64].

\section{Participation Measures}

Four measures of participation were considered by the workgroup to have sufficient levels of evidence to justify use among persons with SCI (Table 1). Characteristics and limitations of each measure are now reviewed.

The CHART tool can be considered the most widely used participation instrument among persons with SCI [16]. The CHART is a 32-item measure that yields scores in domains including physical independence, cognitive independence, mobility, occupation, social integration, and economic self-sufficiency. Validity and reliability of the CHART have been demonstrated in studies of persons with SCI $[16,65]$. The CHART was specifically designed to focus on objective criteria rather than subjective interpretations of participation, such as life satisfaction. Therefore, one important limitation of the CHART is its conceptual exclusion of subjective appraisals of participation. Also, the CHART has significant ceiling effects; more than half of samples of persons with SCI attain maximum scores on most CHART subscales [65]. Consequently, its use for characterizing higher levels of participation is limited and its skewed distribution will impact statistical analyses.

The LIFE-H measures both accomplishment and satisfaction with daily activities and social roles [17]. Conceptually, it is a measure of activities and participation. It is a lengthy instrument, consisting of 77 (short form) or 240 items (long form) that are derived to provide 12 par- ticipation subscales: nutrition, fitness, personal care, communication, housing, mobility, responsibility, interpersonal relations, community, education, employment, and recreation. The measure has demonstrated adequate psychometric qualities [66], including evaluations using IRT and Rasch modeling [67]. The length of the LIFE-H may represent significant burden to respondents and administrators. While the LIFE-H does have a body of published studies demonstrating its strengths, this work was largely done by the developers of the instrument. Many of the "life habits" appraised in the LIFE-H items emphasize motor activity, so the measure has been criticized as being potentially biased against persons with greater motor impairment [15,66].

The IPA is a 32-item measure designed to assess perceived participation and participation restrictions from the point of view of persons with disability [18]. It includes subscales of social relations, autonomy in self-care, mobility and leisure, family role, and work and educational opportunities. Studies have supported its reliability, validity, and factor structure among persons with SCI [18,68-70]. Limitations of the IPA include some floor and ceiling effects and relatively less use empirically than other activity and participation measures [15,71].

The LiSat is a 9-item self-report scale measuring life satisfaction [22]. Conceptually, the instrument can be considered to measure satisfaction with participation [36]. In the LiSat, one global item assesses "life as a whole" while the eight remaining items each addresses satisfaction with a different life domain: vocational situation, financial situation, leisure, friends, sexual life, ADLs, family life, and partnership relationship. The measure was developed for use among the general population, but in recent years it has been in seven published studies of persons with SCI [69]. In these studies, its reliability and factor structure have been supported [72]. Data supporting the measure's validity among persons with SCI are more limited [72].

\section{Measures of Influential Factors}

\section{Psychological Domain}

In the domain of psychological functioning, depression and substance abuse stand out as common comorbid conditions that negatively affect participation after SCI [73-74]. With regard to depression, numerous measures have been studied and no single measure seems preeminent. 
Therefore, we selected five widely used measures to comment upon.

The Beck Depression Inventory (BDI) is the most frequently used measure of depression in SCI, with at least 44 studies on people with SCI published but only 2 with psychometric data [75]. The 21 items are scored on a $0-3$ scale that is unique to each question. The traditional cutoff score for clinically significant depression is 10 or more. However, a validity study comparing the BDI with a Diagnostic and Statistical Manual of Mental Disorders (DSM)-Third Edition-Revised structured clinical interview for depression found that a cutoff of 18 or more resulted in optimal sensitivity (83\%) and specificity (91\%) in people with SCI [76]. Advantages of the BDI are its widespread use and comparison samples, sensitivity to change, and relevance to cognitive-behavioral therapy treatment approaches. Disadvantages are the overall length, lack of parallelism with DSM-Fourth Edition (DSM-IV) nosology, and inclusion of somatic symptoms that may be caused by SCI. The BDI II published in 1996 is shorter and matches DSM-IV symptoms and time frame [77].

The Centers for Epidemiologic Studies-Depression scale (CES-D) is a 20-item scale designed to measure depressive symptoms in the general population [78]. Items are scored on a 4-point Likert scale ranging from 0 (rarely or none of the time) to 3 (most or all of the time) during the past week. The CES-D has been used in at least 37 studies, including 12 with psychometric data and 2 that focused specifically on validity [73]. The CES-D appears unidimensional. The standard cutoff score for determining significant depressive symptoms is 16 or more. However, in a Thai sample, a cutoff of 19 or more resulted in a sensitivity of 80 percent and a specificity of 70 percent compared with a diagnosis of major depression based on psychiatric interview [73]. An advantage of the CES-D is its acceptability and de-emphasis on somatic symptoms. Disadvantages are length and lack of comparability to DSM-IV criteria.

The Patient Health Questionnaire-9 (PHQ-9) is a 9-item screening measure constructed to exactly parallel the DSMIV criteria for major depression [79]. Items are coded on a 0-3 scale from not at all to nearly every day during the past 2 weeks. A total score of 10 or more had the best combination of sensitivity (88\%) and specificity (88\%) when compared with a depression diagnosis in primary care [79]. Responses can be scored according to DSM-IV symptom criteria to increase the specificity of the measure and reduce false positives [79]. The PHQ-9 has been used in at least seven studies of people with SCI, including two designed to measure psychometric properties. No studies have evaluated the diagnostic validity of the PHQ-9 compared with a diagnostic interview for major depression in people with SCI. Advantages of this measure are its brevity, parallelism with DSM-IV criteria, and inclusion of a suicidal ideation item. A limitation of the PHQ-9 is the inclusion of somatic symptoms that may be attributable to SCI or the hospital environment. As with other measures, the likely etiology of somatic symptoms should be considered carefully, especially if the PHQ-9 is used in acute care or inpatient rehabilitation [80].

Substance abuse is also a common comorbid condition in people with SCI. Substance abuse measures may cover consumption, symptoms of dependence, and substance use-related problems or impairment. The Alcohol Use Disorders Identification Test (AUDIT) consists of 10 items covering all 3 domains in a very brief format [81]. The AUDIT has been used in at least one published study of SCI [82]. Using a cutoff or eight or more, the sensitivity and specificity of the AUDIT in detecting alcohol dependence in primary care are 74 and 89 percent, respectively [83]. The three AUDIT consumption questions alone (referred to as the AUDIT-C) are almost as accurate in detecting alcohol dependence as the AUDIT [83].

The World Health Organization (WHO) developed the Alcohol Smoking and Substance Involvement Screening Test (WHO ASSIST) as a screen for lifetime and current (past 3 months) drug use, dependence, and impairment [84]. The WHO ASSIST consists of 8 items covering 10 substances. It is a reliable and valid indicator of drug use and dependence compared with a structured diagnostic interview. No published studies have used the WHO ASSIST in people with SCI. Advantages of the WHO ASSIST over other drug abuse screening measures are its coverage of tobacco, alcohol, and other drugs all in a brief format; the availability of the measure in multiple languages; the strong validity data; and its ability to discriminate low, moderate, and high risk substance use for any substance.

\section{Medical Domain}

Medical complications occur with unfortunate consistency after SCI, with a strong impact on functioning, so measurement of medical comorbidities is recommended as a part of an assessment of activity and participation. Two 
measures were discussed by the SCI workgroup as being of possible utility to investigators (Table 3 ).

The Charlson Comorbidity Index (CCI) identifies and weighs important comorbid conditions that were originally identified as predictors of mortality in a general medical population [85]. With this index, medically diagnosed conditions have preset point values such that those of more severe morbidity risk (e.g., metastatic tumor) are assigned a point value of 6 while less severe ones (e.g., peripheral vascular disease) are assigned 1 point. Patients are assigned weighted points for each condition. The sum total is stratified according to severity (none to mildly ill, moderately ill, severely ill). The weighted index was developed using 1-year survival and tested for its ability to predict 10-year survival [85]. The CCI is not well studied among persons with SCI, and it does not serve as an index of comorbid conditions common after SCI, such as urinary tract infection, pressure ulcers, or spasticity.

The Duke Severity of Illness is a clinician-rated instrument for measuring illness severity or burden. The clinician selects up to three of a patient's most serious illnesses and provides ratings of symptom level, complications, prognosis without treatment, and treatability. Limitations include a modest level of reliability [86] and no validation in persons with physical disability.

\section{Environmental Domain}

Theoretical models of activity and participation recognize the importance of environmental influence.
Within the domain of environmental factors, however, instrument development research has been limited. Rienhardt and Post recently reviewed measures of environmental influences on participation in SCI [87]. Six measures were identified that had been used in SCI populations and had been published with psychometric data. Of those measures reviewed, the Craig Hospital Inventory of Environmental Factors (CHIEF) [88] was described as having superior psychometric performance (Table 3). The CHIEF consists of 25 items that assess the frequency and magnitude of perceived social, attitudinal, policy, and physical/architectural barriers that keep people from doing what they want or need to do. A total score ranging from 0 to 8 is derived, with higher scores indicating great frequency and/or magnitude of environmental barriers. The CHIEF has been tested in persons with SCI and achieved acceptable reliability [88]. CHIEF scores also seem to be associated with the type and severity of the disability. The CHIEF Short Form is a 12item version of the CHIEF that includes those items with the greatest conceptual clarity and discriminant validity. In a study of 2,726 persons with SCI who registered in the SCI Model Systems database, Whiteneck et al. reported that the CHIEF Short Form subscales accounted for only 4 percent or less of the variation in participation [88], which may reflect the limitations of CHIEF, including (1) assessment of barriers but not facilitators, (2) subjective perception rather than more objective criteria, and (3) dichotomization of the scale.

Table 3.

Medical and environmental measures.

\begin{tabular}{|c|c|c|c|c|}
\hline Domain/Measure & Acronym & Description & Limitations & Population \\
\hline \multicolumn{5}{|l|}{ Medical } \\
\hline $\begin{array}{l}\text { Charleson Comorbidity } \\
\text { Index }\end{array}$ & CCI & $\begin{array}{l}\text { Index of general medical comorbidities } \\
\text { used to calculate total score reflecting risk } \\
\text { for mortality. }\end{array}$ & $\begin{array}{l}\text { Does not include SCI- } \\
\text { specific comorbidities. }\end{array}$ & Any \\
\hline Duke Severity of Illness & DUSOI & $\begin{array}{l}\text { Clinician-rated instrument for } \\
\text { measuring illness severity or } \\
\text { burden. }\end{array}$ & $\begin{array}{l}\text { Modest level of reliability. } \\
\text { No validation in persons with } \\
\text { SCI. }\end{array}$ & Any \\
\hline \multicolumn{5}{|l|}{ Environmental } \\
\hline $\begin{array}{l}\text { Craig Hospital Inventory } \\
\text { of Environmental Factors }\end{array}$ & CHIEF & $\begin{array}{l}\text { 25-item measure assessing frequency } \\
\text { and magnitude of perceived social, } \\
\text { attitudinal, policy, and physical/ } \\
\text { architectural barriers to participation. }\end{array}$ & $\begin{array}{l}\text { No facilitator assessment. } \\
\text { Subjective criteria. } \\
\text { Dichotomization of the scale. }\end{array}$ & Any \\
\hline
\end{tabular}


GAPS IN MEASURES OF ACTIVITY, PARTICIPATION, AND INFLUENTIAL FACTORS

Recent research has provided various measures of activity, participation, and influential factors that are adequate for use among persons with SCI. However, investigators should be aware of the limitations of these measures to inform selection and use and to direct future research on measurement development.

A leading concern among available measures is that persons with SCI are not included in the development or psychometric study of the measures. This can contribute to the inclusion of items that are inappropriate for persons that mobilize primarily via wheelchair or to an overemphasis on culturally normative definitions of activity and participation. Similarly, responses to some items in depression measures may be influenced by ordinary somatic experiences of persons with SCI. The ceiling and floor effects noted among a number of measures could also be a result of an absence of persons with SCI in development samples and conceptualizations of activities and participation that are based on the values and experiences of nondisabled persons. Very little is known about the sensitivity to change of measures of activity and participation among persons with SCI.

The SCI workgroup noted an absence of measures of certain important outcomes and influential factors. First, measures tend to focus on deficits and pathology to the exclusion of positive experiences and high functional performance. This tendency is manifested in ceiling effects and selection of pathological constructs, e.g., depression. As compared with activity and participation, relatively few measures of environmental factors are available; perhaps this reflects the complexities inherent in defining and measuring environmental factors. Standardized methods for quantifying healthcare delivery and benefit systems are needed to facilitate understanding of how these factors influence outcomes and for allowing cross-system and international comparisons.

\section{MEASURES IN DEVELOPMENT}

In addition to all the measures that are being used, several future measurement instruments are currently under development, in the process of validation, or nearing the point of published findings that have significant potential to be superior to some older measures (Table 4).
These measures may eventually replace several of the existing measures. They should continue to undergo further consideration for common data elements (CDEs) as evidence of sound psychometric characteristics, normative data, utility in SCI research, and presence in the literature evolve. These future measures will fill some of the existing gaps in measurement of SCI-related sequelae and may employ more sophisticated validation techniques than older measures. Additionally, some of these measures may better facilitate comparison across patient groups (e.g., different disease populations, broader age range). In many respects, future measures are considered by the workgroup to have the potential to be superior to existing measures.

The workgroup acknowledges that the selection of recommended outcome measures is a flexible and dynamic process that will undergo further evolution in the coming years as additional evidence emerges and as testing of these measures as CDEs is undertaken. All the measures listed here have been selected as the best measures at the time of this publication; nevertheless, the workgroup advises that the reader consult the literature for updates to this listing as measures undergo further development and testing.

The Participation Survey/Mobility (PARTS/M) is a survey designed for persons with mobility impairments and based on the ICF definition of participation [89]. Published research on the PARTS/M has been limited beyond the initial study of its statistical properties. The Community Participation Indicators (CPI) [15] is an instrument in development that will integrate objective and subjective definitions of participation. The CPI is currently being pilot tested.

Two measurement systems that have great potential to become leading instruments are the SCI-QOL and SCI-CAT. These are based off of the Patient-Reported Outcomes Measurement Information System (PROMIS) [90] and Neuro-QOL [91] systems being developed by the National Institutes of Health (NIH).

The PROMIS is a new measurement system that was developed as part of NIH Roadmap to improve the clinical research enterprise [92]. The PROMIS Network has developed and tested a large bank of items measuring patient-reported outcomes over several domains, including physical functioning, sleep disturbance, fatigue, anxiety, depression, anger, social roles, and social activities [93-94]. Item banks have been calibrated, allowing tests to be administered as a CAT or as short forms to ensure 
JRRD, Volume 49, Number 1, 2012

Table 4.

Measures in development.

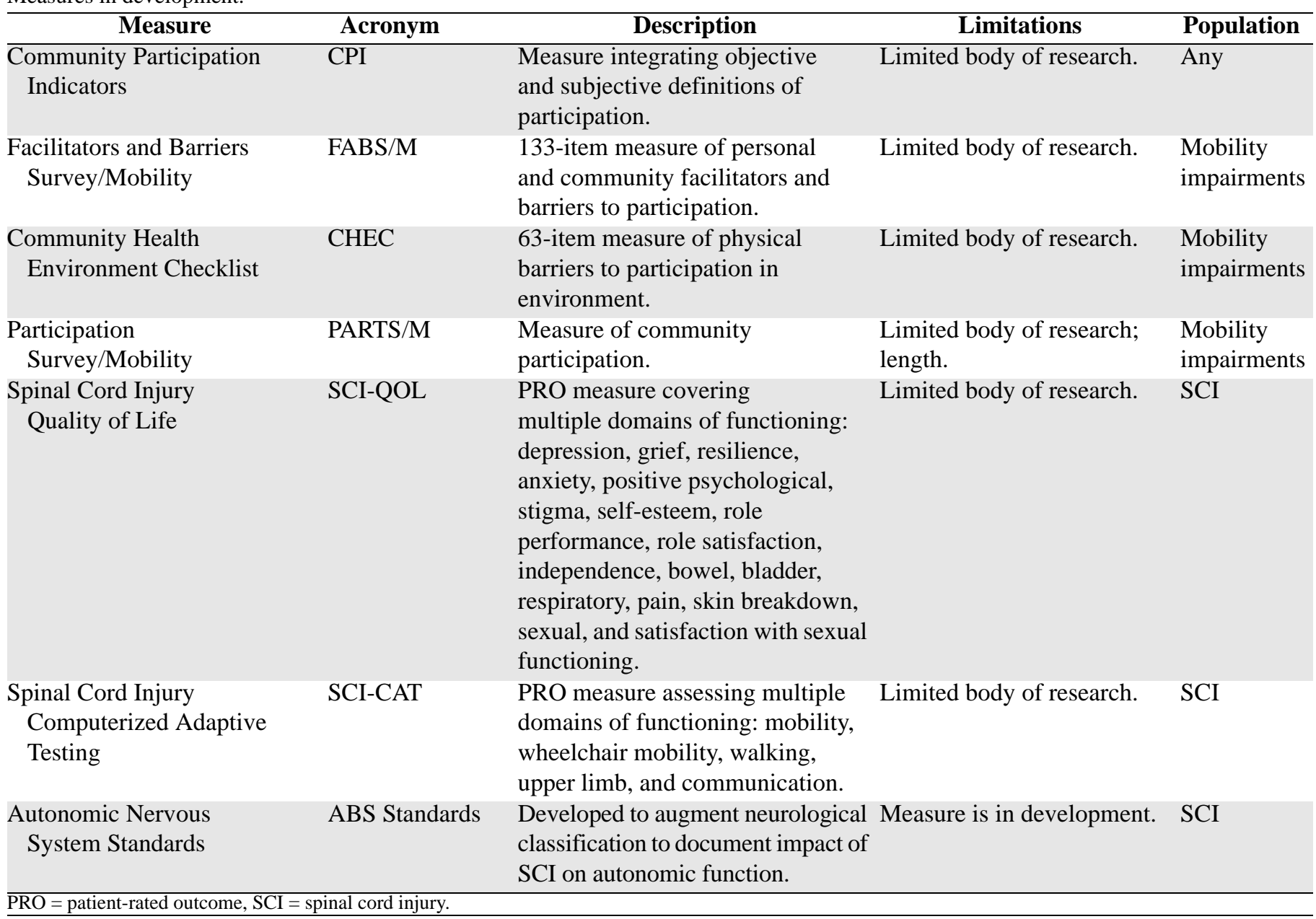

the assessment is brief. The measure is designed as a generic measure to be used across all medical populations.

The Neuro-QOL is also a patient-rated outcome (PRO) measurement system funded through a contract method by the National Institute on Neurological Disorders and Stroke (NINDS) [95]. The Neuro-QOL team has developed separate item banks covering the following domains: mobility/ambulation, ADL/upper limb, depression, anxiety, positive psychological functioning, stigma, perceived and applied cognition (includes communication), social role performance, social role satisfaction, fatigue, personality and behavioral change, and sleep disturbances. Embedded in several of the Neuro-QOL domains are a significant number of PROMIS items and attempts will be made to link the PROMIS and NeuroQOL measures. The Neuro-QOL is designed to provide PROs for clinical trials research sponsored by the NINDS.
The SCI-QOL is a new multifaceted PRO measure of functioning under development that is cofunded by the National Institute of Child Health and Human Development/National Center for Medical Rehabilitation Research and the NINDS that embeds Neuro-QOL and PROMIS items. Separate item banks are being developed to measure bowel maintenance/functioning, bladder maintenance, bladder complications, pain, skin breakdown, depression, grief/loss, resilience, anxiety, positive psychological functioning, stigma, social role performance, social role satisfaction, independence/autonomy, sexual functioning, and satisfaction with sexual functioning [96]. The SCI-QOL calibration item banks include all the relevant Neuro-QOL items along with several PROMIS items to provide linkages between these systems with the goal of creating equivalency score, allowing individuals who complete the SCI-QOL to also receive a Neuro-QOL 
score and a PROMIS equivalency score. Because the SCIQOL and SCI-CAT systems have been developed with the input of individuals with SCI, these measures should expand upon the Neuro-QOL and PROMIS measurement systems with items and item banks that expand the specificity of the instrument. A collaborative team involving the University of Michigan, Kessler Foundation/Kessler Institute for Rehabilitation, Rehabilitation Institute of Chicago, Craig Hospital, University of Washington, Northwestern University, and the James J. Peters VA participated in the large field testing of the items involving more than 900 individuals with traumatic SCI. Calibrated item banks are being developed and validation studies examining responsiveness to change, convergent and discriminant validity, and test-retest reliability will be conducted as two validation studies. A grant from the VA RR\&D has been awarded to the James J. Peters VA to validate the SCI-QOL in VA-based samples.

The SCI-CAT is a new, multifaceted PRO measure to assess activity limitation/functional activities in individuals with SCI and was funded by the NIDRR as part of the Spinal Cord Injury Model Systems Program [97]. Like the measurement systems just discussed, the SCI-CAT has embedded items from the Neuro-QOL and PROMIS physical functioning, mobility, and upper-limb item banks with the potential of linking scores between the measures. The SCI-CAT includes calibrated item banks for basic mobility, wheelchair mobility, ambulation, selfcare, and fine motor functioning. Six model systems centers (University of Michigan, Boston University, Kessler Foundation/Kessler Institute for Rehabilitation, Rehabilitation Institute of Chicago, Craig Hospital, and Mount Sinai Medical Center) have participated in the development of the SCI-CAT and field tested the scale in a sample of 855 individuals with traumatic SCI.

In the physical domain, the Thoracic-Lumbar control (Trunk) Scale is currently in development. The Trunk Scale is designed to measure voluntary control of the trunk musculature after SCI [98]. As restorative and regenerative therapies are being developed and accepted clinically, the need has arisen for measures that are more sensitive to the changes in motor control that may result from these interventions. The Trunk Scale is intended to measure motor ability in the thoracic segments (thoracic 2 to lumbar 1), which is not measured by the International Standards for the Neurological Classification of Spinal Cord Injury (ISNCSCI) Impairment Scale [99], significantly reducing sensitivity to change and associa- tions with function [100]. The Trunk Scale is designed to be sensitive to quality of movement: it distinguishes between functional tasks performed through use of an assistive device(s), orthotic(s), and/or compensatory techniques often taught in traditional SCI rehabilitation versus those tasks/movements performed in a "preinjury" or "noninjured" movement pattern. This sensitivity is one of the key features missing from several existing measures of function, including the FIM and the 10MWT.

Other researchers are working to standardize the measurement of medical complications that can impair participation after SCI. For example, autonomic dysfunction is known to be a common consequence of SCI during both the acute and chronic phases. Autonomic nervous system dysfunction can delay rehabilitation, impair ADL independence and QOL, predispose the person with SCI to developing degenerative pathologies (atherosclerotic heart disease, impaired glucose metabolism, etc.), and may be life threatening (autonomic dysreflexia). The ISNCSCI Impairment Scale was developed to document impairments of motor and sensory function after SCI, but lacks the ability to assess intactness of autonomic function after SCI [99]. The American Spinal Injury Association, the International Spinal Cord Society, and other groups performing SCI research recommend the addition of autonomic standards to the ISNCSCI Impairment Scale to describe the effects of SCI on bowel, bladder, sexual, cardiovascular, broncho-pulmonary, sudomotor, and other autonomic functions. The Autonomic Standards Assessment Form was developed as a new tool meant to augment the ISNCSCI Impairment Scale in order to document the impact of SCI on autonomic function.

Two measures of environmental influence on participation have recently been developed. The Community Health Environment Checklist is a 63-item measure of physical barriers in the environment that can restrict community participation among persons with mobility impairments [101]. The Facilitators and Barriers Survey/ Mobility (FABS/M) is a 133-item measure of facilitators and barriers to participation among persons with mobility impairments [102]. The FABS/M assesses barriers and facilitators to participation at the level of individual and community.

\section{FUTURE DIRECTIONS FOR RESEARCH}

The SCI workgroup comprised individuals representing SCI Model Systems institutions and VA SCI/D 
specialty care centers. This arrangement prompted the reflection that increased collaboration between these organizations could represent an avenue for increasing our understanding of measurement of outcomes after SCI/D, such as activity and participation. The workgroup recommended consideration of methods for greater alignment of outcome measures and outcome measurement studies across VA and Model Systems sites, pursuit of opportunities for interagency funding, and coordination of statistical analyses. In discussing these possibilities, the workgroup acknowledged that the SCI Model Systems sites and the VA have different approaches to healthcare and outcomes and serve dissimilar populations. Interpreting direct comparisons of outcomes between these systems would be difficult; e.g., Would any differences in outcomes be due to population characteristics, systems of care, measurement methods, or multiple factors? Noting those complications, intriguing options for collaborative work remain. For example, large-scale efforts to examine the psychometric performance of outcomes measures could be coordinated. Efforts to provide the field with benchmarks of expected outcomes after SCI/D [103] could be organized across systems.

\section{CONCLUSIONS}

Activity and participation represent critical outcomes for persons with SCI/D and yet existing measurement tools in this population have significant limitations. Investigators are encouraged to become aware of the flaws in available measures in order to make informed decisions for specific projects. A number of measures are available that can serve as indices of activity, participation, and influential factors until the next generation of instruments is developed and disseminated.

\section{ACKNOWLEDGMENTS}

\author{
Author Contributions: \\ Study concept and design: P. M. Ullrich, A. M. Spungen. \\ Acquisition of data: P. M. Ullrich, A. M. Spungen, D. Atkinson, \\ C. H. Bombardier, Y. Chen, N. A. Erosa, S. Groer, L. Ottomanelli, \\ D. S. Tulsky. \\ Analysis and interpretation of data: P. M. Ullrich, A. M. Spungen, \\ D. Atkinson, C. H. Bombardier, Y. Chen, N. A. Erosa, S. Groer, \\ L. Ottomanelli, D. S. Tulsky. \\ Drafting of manuscript: P. M. Ullrich, A. M. Spungen, D. Atkinson, \\ C. H. Bombardier, Y. Chen, S. Groer, D. S. Tulsky.
}

Critical revision of manuscript for important intellectual content: P. M. Ullrich, A. M. Spungen, D. Atkinson, C. H. Bombardier, Y. Chen, N. A. Erosa, S. Groer, L. Ottomanelli, D. S. Tulsky. Administrative, technical, or material support: P. M. Ullrich, A. M. Spungen, D. Atkinson, C. H. Bombardier, Y. Chen, N. A. Erosa, S. Groer, L. Ottomanelli, D. S. Tulsky.

Study supervision: P. M. Ullrich, A. M. Spungen.

Financial Disclosures: The authors have declared that no competing interests exist.

Funding/Support: This material is the result of work supported by VA RR\&D Service.

Additional Contributions: The authors gratefully acknowledge the guidance of anonymous reviewers.

Disclaimer: This articles presents the views of the authors; it does not necessarily represent the views or policies of VA.

\section{REFERENCES}

1. Donovan WH. Donald Munro lecture: Spinal cord injury_Past, present, future. J Spinal Cord Med. 2007; 30(2):85-100. [PMID: 17591221]

2. Fonseca JE. The Donald Munro memorial lecture. The VA and spinal cord injury: A record of service. J Am Paraplegia Soc. 1987;10(1):8-11. [PMID: 3553429]

3. Fact sheet: VA and spinal cord injury [Internet]. Washington (DC): Department of Veterans Affairs; 2009 [updated 2009 Jan; cited 2010 May]. Available from:

http://www1.va.gov/opa/publications/factsheets/ fs spinal cord injury.pdf

4. Tulsky DS, Rosenthal M. Quality of life measurement in rehabilitation medicine: Building an agenda for the future. Arch Phys Med Rehabil. 2002;83(12 Suppl 2):S1-3. [PMID: 12474165] http://dx.doi.org/10.1053/apmr.2002.36954

5. Tulsky DS, Rosenthal M. Measurement of quality of life in rehabilitation medicine: Emerging issues. Arch Phys Med Rehabil. 2003;84(4 Suppl 2):S1-2. [PMID: 12692765] http://dx.doi.org/10.1053/apmr.2003.50203

6. Kaplan RM. Quality of life: An outcomes perspective. Arch Phys Med Rehabil. 2002;83(12 Suppl 2):S44-50. [PMID: 12474171] http://dx.doi.org/10.1053/apmr.2002.36955

7. Tate DG, Kalpakjian CZ, Forchheimer MB. Quality of life issues in individuals with spinal cord injury. Arch Phys Med Rehabil. 2002;83(12 Suppl 2):S18-25.

[PMID: 12474168] http://dx.doi.org/10.1053/apmr.2002.36835

8. Hays RD, Hahn H, Marshall G. Use of the SF-36 and other health-related quality of life measures to assess persons with disabilities. Arch Phys Med Rehabil. 2002;83(12 Suppl 2):S4-9. [PMID: 12474166] http://dx.doi.org/10.1053/apmr.2002.36837 
9. Hammel J, Magasi S, Heinemann A, Whiteneck G, Bogner J, Rodriguez E. What does participation mean? An insider perspective from people with disabilities. Disabil Rehabil. 2008;30(19):1445-60. [PMID: 18923977] http://dx.doi.org/10.1080/09638280701625534

10. Magasi S, Hammel J, Heinemann A, Whiteneck G, Bogner J. Participation: A comparative analysis of multiple rehabilitation stakeholders' perspectives. J Rehabil Med. 2009;41(11):936-44. [PMID: 19841847] http://dx.doi.org/10.2340/16501977-0450

11. Dijkers M. Quality of life after spinal cord injury: A meta analysis of the effects of disablement components. Spinal Cord. 1997;35(12):829-40. [PMID: 9429262]

http://dx.doi.org/10.1038/sj.sc.3100571

12. Heinemann AW. State-of-the-science on postacute rehabilitation: Setting a research agenda and developing an evidence base for practice and public policy. An introduction. Arch Phys Med Rehabil. 2007;88(11):1478-81.

[PMID: 17964892]

http://dx.doi.org/10.1016/j.apmr.2007.05.030

13. Clohan DB, Durkin EM, Hammel J, Murray P, Whyte J, Dijkers M, Gans BM, Graves DE, Heinemann AW, Worsowicz G. Postacute rehabilitation research and policy recommendations. Arch Phys Med Rehabil. 2007;88(11): 1535-41. [PMID: 17964901] http://dx.doi.org/10.1016/j.apmr.2007.07.022

14. Duncan PW, Velozo CA. State-of-the-science on postacute rehabilitation: Measurement and methodologies for assessing quality and establishing policy for postacute care. Arch Phys Med Rehabil. 2007;88(11):1482-87. [PMID: 17964893]

http://dx.doi.org/10.1016/j.apmr.2007.08.118

15. Magasi SR, Heinemann AW, Whiteneck GG; Quality of Life/Participation Committee. Participation following traumatic spinal cord injury: An evidence-based review for research. J Spinal Cord Med. 2008;31(2):145-56. [PMID: 18581661]

16. Whiteneck GG, Charlifue SW, Gerhart KA, Overholser JD, Richardson GN. Quantifying handicap: A new measure of long-term rehabilitation outcomes. Arch Phys Med Rehabil. 1992;73(6):519-26. [PMID: 1622299]

17. Fougeyrollas P, Noreau L, Bergeron H, Cloutier R, Dion SA, St-Michel G. Social consequences of long term impairments and disabilities: Conceptual approach and assessment of handicap. Int J Rehabil Res. 1998;21(2): 127-41. [PMID: 9924676] http://dx.doi.org/10.1097/00004356-199806000-00002

18. Cardol M, De Haan RJ, Van den Bos GA, De Jong BA, De Groot IJ. The development of a handicap assessment questionnaire: The Impact on Participation and Autonomy (IPA). Clin Rehabil. 1999;13(5):411-19.

\section{[PMID: 10498348]}

http://dx.doi.org/10.1191/026921599668601325

19. Noonan VK, Kopec JA, Noreau L, Singer J, Masse LC, Zhang H, Dvorak MF. Measuring participation among persons with spinal cord injury: Comparison of three instruments. Top Spinal Cord Inj Rehabil. 2010;15(4): 49-62. http://dx.doi.org/10.1310/sci1504-49

20. Post MW, De Witte LP, Van Asbeck FW, Van Dijk AJ, Schrijvers AJ. Predictors of health status and life satisfaction in spinal cord injury. Arch Phys Med Rehabil. 1998;79(4):395-402. [PMID: 9552104] http://dx.doi.org/10.1016/S0003-9993(98)90139-3

21. World Health Organization. International Classification of Functioning, Disability and Health (ICF). Geneva (Switzerland): World Health Organization; 2001.

22. Fugl-Meyer A, Bränholm I, Fugl-Meyer KS. Happiness and domain-specific life satisfaction in adult northern Swedes. Clin Rehabil. 1991;5(1):25-33. http://dx.doi.org/10.1177/026921559100500105

23. Whiteneck G, Dijkers MP. Difficult to measure constructs: Conceptual and methodological issues concerning participation and environmental factors. Arch Phys Med Rehabil. 2009;90(11 Suppl):S22-35. [PMID: 19892071] http://dx.doi.org/10.1016/j.apmr.2009.06.009

24. Larson RJ, Welch HG. Risk for increased utilization and adverse health outcomes among men served by the Veterans Health Administration. Mil Med. 2007;172(7):690-96. [PMID: 17691680]

25. McKinney WP, McIntire DD, Carmody TJ, Joseph A. Comparing the smoking behavior of veterans and nonveterans. Public Health Rep. 1997;112(3):212-18. [PMID: 9160055]

26. Winkleby MA, Fleshin D. Physical, addictive, and psychiatric disorders among homeless veterans and nonveterans. Public Health Rep. 1993;108(1):30-36. [PMID: 8434094$]$

27. Ginis KA, Latimer AE, Hicks AL, Craven BC. Development and evaluation of an activity measure for people with spinal cord injury. Med Sci Sports Exerc. 2005;37(7):1099-1111. [PMID: 16015125] http://dx.doi.org/10.1249/01.mss.0000170127.54394.eb

28. Hetz SP, Latimer AE, Ginis KA. Activities of daily living performed by individuals with SCI: Relationships with physical fitness and leisure time physical activity. Spinal Cord. 2009;47(7):550-54. [PMID: 19104510]

http://dx.doi.org/10.1038/sc.2008.160

29. Latimer AE, Ginis KA, Craven BC, Hicks AL. The physical activity recall assessment for people with spinal cord injury: Validity. Med Sci Sports Exerc. 2006;38(2):208-16. [PMID: 16531886] http://dx.doi.org/10.1249/01.mss.0000183851.94261.d2

30. Catz A, Itzkovich M, Agranov E, Ring H, Tamir A. SCIMSpinal Cord Independence Measure: A new disability scale 
for patients with spinal cord lesions. Spinal Cord. 1997;35(12):850-56. [PMID: 9429264]

http://dx.doi.org/10.1038/sj.sc.3100504

31. Itzkovich M, Tripolski M, Zeilig G, Ring H, Rosentul N, Ronen J, Spasser R, Gepstein R, Catz A. Rasch analysis of the Catz-Itzkovich Spinal Cord Independence Measure. Spinal Cord. 2002;40(8):396-407. [PMID: 12124666] http://dx.doi.org/10.1038/sj.sc.3101315

32. Catz A, Itzkovich M, Tesio L, Biering-Sorensen F, Weeks C, Laramee MT, Craven BC, Tonack M, Hitzig SL, Glaser E, Zeilig G, Aito S, Scivoletto G, Mecci M, Chadwick RJ, El Masry WS, Osman A, Glass CA, Silva P, Soni BM, Gardner BP, Savic G, Bergström EM, Bluvshtein V, Ronen J. A multicenter international study on the Spinal Cord Independence Measure, version III: Rasch psychometric validation. Spinal Cord. 2007;45(4):275-91.

[PMID: 16909143]

33. Guide for the uniform data set for medical rehabilitation: (including the FIM instrument), version 5.1. Buffalo (NY): State University of New York at Buffalo; 1997.

34. Ottenbacher KJ, Hsu Y, Granger CV, Fiedler RC. The reliability of the Functional Independence Measure: A quantitative review. Arch Phys Med Rehabil. 1996;77(12): 1226-32. [PMID: 8976303] http://dx.doi.org/10.1016/S0003-9993(96)90184-7

35. Linacre JM, Heinemann AW, Wright BD, Granger CV, Hamilton BB. The structure and stability of the Functional Independence Measure. Arch Phys Rehabil. 1994; 75(2):127-32. [PMID: 8311667]

36. Hall KM, Cohen ME, Wright J, Call M, Werner P. Characteristics of the Functional Independence Measure in traumatic spinal cord injury. Arch Phys Med Rehabil. 1999;80(11): 1471-76. [PMID: 10569443] http://dx.doi.org/10.1016/S0003-9993(99)90260-5

37. Dodds TA, Martin DP, Stolov WC, Deyo RA. A validation of the Functional Independence Measurement and its performance among rehabilitation inpatients. Arch Phys Med Rehabil. 1993;74(5):531-36. [PMID: 8489365$]$ http://dx.doi.org/10.1016/0003-9993(93)90119-U

38. Van Uden C, Besser M. Test-retest reliability of temporal and spatial gait characteristics measured with an instrumented walkway system (GAITRite). BMC Musculoskelet Disord. 2004;5:13. [PMID: 15147583]

http://dx.doi.org/10.1186/1471-2474-5-13

39. Webster KE, Wittwer JE, Feller JA. Validity of the GAITRite walkway system for the measurement of averaged and individual step parameters of gait. Gait Posture. 2005;22(4):317-21. [PMID: 16274913] http://dx.doi.org/10.1016/j.gaitpost.2004.10.005

40. Asato KT, Cooper RA, Robertson RN, Ster JF. SMARTWheels: Development and testing of a system for measuring manual wheelchair propulsion dynamics. IEEE Trans
Biomed Eng. 1993;40(12):1320-24. [PMID: 8125507] http://dx.doi.org/10.1109/10.250587

41. Shimada SD, Robertson RN, Bonninger ML, Cooper RA. Kinematic characterization of wheelchair propulsion. J Rehabil Res Dev. 1998;35(2):210-18. [PMID: 9651893]

42. Cooper RA. SMARTWheel: From concept to clinical practice. Prosthet Orthot Int. 2009;33(3):198-209.

[PMID: 19658010]

http://dx.doi.org/10.1080/03093640903082126

43. Duncan PW, Sullivan KJ, Behrman AL, Azen SP, Wu SS, Nadeau SE, Dobkin BH, Rose DK, Tilson JK; LEAPS Investigative Team. Protocol for the Locomotor Experience Applied Post-stroke (LEAPS) trial: A randomized controlled trial. BMC Neurol. 2007;7:39.

[PMID: 17996052]

ttp://dx.doi.org/10.1186/1471-2377-7-39

44. Perry J, Garrett M, Gronley JK, Mulroy SJ. Classification of walking handicap in the stroke population. Stroke. 1995;26(6):982-89. [PMID: 7762050] http://dx.doi.org/10.1161/01.STR.26.6.982

45. Tilson JK, Sullivan KJ, Cen SY, Rose DK, Koradia CH, Azen SP, Duncan PW; Locomotor Experience Applied Post Stroke (LEAPS) Investigative Team. Meaningful gait speed improvement during the first 60 days poststroke: Minimal clinically important difference. Phys Ther. 2010; 90(2):196-208. [PMID: 20022995]

http://dx.doi.org/10.2522/ptj.20090079

46. Van Hedel HJ, Wirz M, Dietz V. Assessing walking ability in subjects with a spinal cord injury: Validity and reliability of 3 walking tests. Arch Phys Med Rehabil. 2005;86(2):190-96. [PMID: 15706542]] http://dx.doi.org/10.1016/j.apmr.2004.02.010

47. Van Hedel HJ, Wirz M, Dietz V. Standardized assessment of walking capacity after spinal cord injury: The European network approach. Neurol Res. 2008;30(1):61-73. [PMID: 17767814$]$ http://dx.doi.org/10.1179/016164107X230775

48. Van Hedel HJ, Wirz M, Curt A. Improving walking assessment in subjects with an incomplete spinal cord injury: Responsiveness. Spinal Cord. 2006;44(6):352-56. [PMID: 16304565] http://dx.doi.org/10.1038/sj.sc.3101853

49. Sherwood AM, Dimitrijevic MR, McKay WB. Evidence of subclinical brain influence in clinically complete spinal cord injury: Discomplete SCI. J Neurol Sci. 1992;110(1-2): 90-98. [PMID: 1506875] http://dx.doi.org/10.1016/0022-510X(92)90014-C

50. Sherwood AM, Priebe MM, Graves DE. Consistency of multi-channel surface EMG recordings: Application in spinal cord injured subjects. J Electromyogr Kinesiol. 1997;7(2):97111. [PMID: 20719695] http://dx.doi.org/10.1016/S1050-6411(96)00027-2 
51. Sherwood AM, Graves DE, Priebe MM. Altered motor control and spasticity after spinal cord injury: Subjective and objective assessment. J Rehabil Res Dev. 2000; 37(1):41-52. [PMID: 10847571]

52. Dimitrijevic MM, Dimitrijevic MR, Illis LS, Nakajima K, Sharkey PC, Sherwood AM. Spinal cord stimulation for the control of spasticity in patients with chronic spinal cord injury: I. Clinical observations. Cent Nerv Syst Trauma. 1986;3(2):129-44. [PMID: 3490312]

53. Ditunno JF Jr, Ditunno PL, Graziani V, Scivoletto G, Bernardi M, Castellano V, Marchetti M, Barbeau H, Frankel HL, D'Andrea Greve JM, Ko HY, Marshall R, Nance P. Walking Index for Spinal Cord Injury (WISCI): An international multicenter validity and reliability study. Spinal Cord. 2000;38(4):234-43. [PMID: 10822394$]$ http://dx.doi.org/10.1038/sj.sc.3100993

54. Ditunno PL, Ditunno JF Jr. Walking Index for Spinal Cord Injury (WISCI II): Scale revision. Spinal Cord. 2001;39(12): 654-56. [PMID: 11781863]

http://dx.doi.org/10.1038/sj.sc.3101223

Erratum in Spinal Cord. 2009;47(4):349.

55. Morganti B, Scivoletto G, Ditunno P, Ditunno JF, Molinari M. Walking Index for Spinal Cord Injury (WISCI): Criterion validation. Spinal Cord. 2005;43(1):27-33.

[PMID: 15520841$]$

http://dx.doi.org/10.1038/sj.sc.3101658

56. Field-Fote EC, Fluet GG, Schafer SD, Schneider EM, Smith R, Downey PA, Ruhl CD. The Spinal Cord Injury Functional Ambulation Inventory (SCI-FAI). J Rehabil Med. 2001;33(4):177-81. [PMID: 11506216] http://dx.doi.org/10.1080/165019701750300645

57. Berg KO, Wood-Dauphinee SL, Williams JI, Maki B. Measuring balance in the elderly: Validation of an instrument. Can J Public Health. 1992;83 Suppl 2:S7-S11. [PMID: 1468055$]$

58. Berg K, Wood-Dauphinee S, Williams JI. The Balance Scale: Reliability assessment with elderly residents and patients with an acute stroke. Scand J Rehabil Med. 1995; 27(1):27-36. [PMID: 7792547]

59. Shumway-Cook A, Baldwin M, Polissar NL, Gruber W. Predicting the probability for falls in community-dwelling older adults. Phys Ther. 1997;77(8):812-19. [PMID: 9256869]

60. O’Sullivan SB, Schmitz TJ. Physical rehabilitation. 5th ed. Philadelphia (PA): F. A. Davis; 2007.

61. Datta S, Lorenz DJ, Morrison S, Ardolino E, Harkema SJ. A multivariate examination of temporal changes in Berg Balance Scale items for patients with ASIA Impairment Scale C and D spinal cord injuries. Arch Phys Med Rehabil. 2009;90(7):1208-17. [PMID: 19577035] http://dx.doi.org/10.1016/j.apmr.2008.09.577

62. Chaves ES, Boninger ML, Cooper R, Fitzgerald SG, Gray DB, Cooper RA. Assessing the influence of wheel- chair technology on perception of participation in spinal cord injury. Arch Phys Med Rehabil. 2004;85(11):185458.

[PMID: 15520981$]$

http://dx.doi.org/10.1016/j.apmr.2004.03.033

63. Warms C. Physical activity measurement in persons with chronic and disabling conditions: Methods, strategies, and issues. Fam Community Health. 2006;29(1 Suppl):78S-88S. [PMID: 16344640]

64. Kirby RL, Dupuis DJ, MacPhee AH, Coolen AL, Smith C, Best KL, Newton AM, Mountain AD, MacLeod DA, Bonaparte JP. The Wheelchair Skills Test (version 2.4): Measurement properties. Arch Phys Med Rehabil. 2004;85(5):794-804. [PMID: 15129405] http://dx.doi.org/10.1016/j.apmr.2003.07.007

65. Hall KM, Dijkers MP, Whiteneck GG, Brooks CA, Krause JS. The Craig Handicap Assessment and Reporting Technique (CHART): Metric properties and scoring. Top Spinal Cord Inj Rehabil. 1998;4(1):16-30. http://dx.doi.org/10.1310/V5RU-FRFE-50E6-E2NA

66. Dijkers MP, Whiteneck G, El-Jaroudi R. Measures of social outcomes in disability research. Arch Phys Med Rehabil. 2000;81(12 Suppl 2):S63-S80. [PMID: 11128906] http://dx.doi.org/10.1053/apmr.2000.20627

67. Dumont C, Bertrand R, Fougeyrollas P, Gervais M. Rasch modeling and the measurement of social participation. J Appl Meas. 2003;4(4):309-25. [PMID: 14523252]

68. Cardol M, De Haan RJ, De Jong BA, Van den Bos GA, De Groot IJ. Psychometric properties of the Impact on Participation and Autonomy Questionnaire. Arch Phys Med Rehabil. 2001;82(2):210-16. [PMID: 11239312] http://dx.doi.org/10.1053/apmr.2001.18218

69. Larsonn Lund M, Nordlund A, Nygård L, Lexell J, Bernspång $\mathrm{B}$. Perceptions of participation and predictors of perceived problems with participation in people with spinal cord injury. J Rehabil Med. 2005;37(1):3-8. [PMID: 15788326] http://dx.doi.org/10.1080/16501970410031246

70. Lund ML, Fisher AG, Lexell J, Bernspång B. Impact on participation and autonomy questionnaire: Internal scale validity of the Swedish version for use in people with spinal cord injury. J Rehabil Med. 2007;39(2):156-62. [PMID: 17351699] http://dx.doi.org/10.2340/16501977-0031

71. Noonan VK, Miller WC, Noreau L; SCIRE Research Team. A review of instruments assessing participation in persons with spinal cord injury. Spinal Cord. 2009;47(6): 435-46. [PMID: 19238163] http://dx.doi.org/10.1038/sc.2008.171

72. Post MW. Measuring the subjective appraisal of participation with life satisfaction measures: Bridging the gap between participation and quality of life measurement. 
Top Spinal Cord Inj Rehabil. 2010;15(4):1-15. http://dx.doi.org/10.1310/sci1504-1

73. Kalpakjian CZ, Bombardier CH, Schomer K, Brown PA, Johnson KL. Measuring depression in persons with spinal cord injury: A systematic review. J Spinal Cord Med. 2009;32(1):6-24. [PMID: 19264045]

74. Tate DG, Forchheimer MB, Krause JS, Meade MA, Bombardier CH. Patterns of alcohol and substance use in persons with spinal cord injury: Risk factors and correlates. Arch Phys Med Rehabil. 2004;85(11):1837-47.

[PMID: 15520979] http://dx.doi.org/10.1016/j.apmr.2004.02.022

75. Beck AT, Ward CH, Mendelson M, Mock J, Erbaugh J. An inventory for measuring depression. Arch Gen Psychiatry. 1961;4:561-71. [PMID: 13688369] http://dx.doi.org/10.1001/archpsyc.1961.01710120031004

76. Radnitz CL, McGrath RE, Tirch DD, Willard J, PerezStrumololo L, Festa J, Binks M, Broderick CP, Schlein IS, Walczak S, Lillian LB. Use of the Beck Depression Inventory in veterans with spinal cord injury. Rehabil Psychol. 1997;42(2):93-101.

http://dx.doi.org/10.1037/0090-5550.42.2.93

77. Beck AT, Steer RA, Brown GK. Manual for the Beck Depression Inventory-II. San Antonio (TX): Psychological Corporation; 1996.

78. Radloff L. The CES-D scale: A self-report depression scale for research in the general population. Appl Psychol Measure. 1977;1(3):385-401. http://dx.doi.org/10.1177/014662167700100306

79. Kroenke K, Spitzer RL, Williams JB. The PHQ-9: Validity of a brief depression severity measure. J Gen Intern Med. 2001;16(9):606-13. [PMID: 11556941] http://dx.doi.org/10.1046/j.1525-1497.2001.016009606.x

80. Krause JS, Reed KS, McArdle JJ. Prediction of somatic and non-somatic depressive symptoms between inpatient rehabilitation and follow-up. Spinal Cord. 2010;48(3): 239-44. [PMID: 19736559] http://dx.doi.org/10.1038/sc.2009.113

81. Allen JP, Litten RZ, Fertig JB, Babor T. A review of research on the Alcohol Use Disorders Identification Test (AUDIT). Alcohol Clin Exp Res. 1997;21(4):613-19. [PMID: 9194913] http://dx.doi.org/10.1111/j.1530-0277.1997.tb03811.x

82. Osteråker AL, Levi R. Indicators of psychological distress in postacute spinal cord injured individuals. Spinal Cord. 2005;43(4):223-29. [PMID: 15583705] http://dx.doi.org/10.1038/sj.sc.3101703

83. Bradley KA, DeBenedetti AF, Volk RJ, Williams EC, Frank D, Kivlahan DR. AUDIT-C as a brief screen for alcohol misuse in primary care. Alcohol Clin Exp Res. 2007;31(7):1208-17. [PMID: 17451397] http://dx.doi.org/10.1111/j.1530-0277.2007.00403.x
84. Humeniuk R, Ali R. Validation of the Alcohol, Smoking and Substance Involvement Screening Test (ASSIST) and pilot brief intervention: A technical report of phase II findings of the WHO ASSIST Project [Internet]. Geneva (Switzerland): World Health Organization; 2006. Available from: http://www.who.int/substance_abuse/activities/assist technicalreport phase2 final.pdf

85. Charlson ME, Pompei P, Ales KL, MacKenzie CR. A new method of classifying prognostic comorbidity in longitudinal studies: Development and validation. J Chronic Dis. 1987;40(5):373-83. [PMID: 3558716] http://dx.doi.org/10.1016/0021-9681(87)90171-8

86. Parkerson GR Jr, Broadhead WE, Tse CK. The Duke Severity of Illness Checklist (DUSOI) for measurement of severity and comorbidity. J Clin Epidemiol. 1993;46(4): 379-93. [PMID: 8483003] http://dx.doi.org/10.1016/0895-4356(93)90153-R

87. Reinhardt JD, Post MW. Measurement and evidence of environmental determinants of participation in spinal cord injury: A systematic review of the literature. Top Spinal Cord Inj Rehabil. 2010;15(4):26-48.

http://dx.doi.org/10.1310/sci1504-26

88. Whiteneck GG, Harrison-Felix CL, Mellick DC, Brooks CA, Charlifue SB, Gerhart KA. Quantifying environmental factors: A measure of physical, attitudinal, service, productivity, and policy barriers. Arch Phys Med Rehabil. 2004;85(8):1324-35. [PMID: 15295760] http://dx.doi.org/10.1016/j.apmr.2003.09.027

89. Gray DB, Hollingsworth HH, Stark SL, Morgan KA. Participation survey/mobility: Psychometric properties of a measure of participation for people with mobility impairments and limitations. Arch Phys Med Rehabil. 2006; 87(2):189-97. [PMID: 16442971] http://dx.doi.org/10.1016/j.apmr.2005.09.014

90. Patient Reported Outcomes Measurement Information System [Internet]. Washington (DC): National Institutes of Health; 2010 [cited 2010 Dec]. Available from: http://www.nihpromis.org/default.aspx

91. Neuro-QOL: Quality of life in neurological disorders [Internet]. Washington (DC): National Institutes of Health; 2010 [cited 2010 Dec]. Available from:

http://www.neuroqol.org/default.aspx

92. Quatrano LA, Cruz TH. Future of outcomes measurement: Impact on research in medical rehabilitation and neurologic populations. Arch Phys Med Rehabil. 2011; 92(10 Suppl):S7-S11. [PMID: 21958925] http://dx.doi.org/10.1016/j.apmr.2010.08.032

93. Cella D, Riley W, Stone A, Rothrock N, Reeve B, Yount S, Amtmann D, Bode R, Buysse D, Choi S, Cook K, Devellis R, DeWalt D, Fries JF, Gershon R, Hahn EA, Lai JS, Pilkonis P, Revicki D, Rose M, Weinfurt K, Hays R; PROMIS Cooperative Group. The Patient-Reported Outcomes 
Measurement Information System (PROMIS) developed and tested its first wave of adult self-reported health outcome item banks: 2005-2008. J Clin Epidemiol. 2010; 63(11):1179-94. [PMID: 20685078] http://dx.doi.org/10.1016/j.jclinepi.2010.04.011

94. Amtmann D, Cook KF, Johnson, KL, Cella D. The PROMIS initiative: Involvement of rehabilitation stakeholders in development and examples of applications in rehabilitation research. Arch Phys Med Rehabil. 2011;92(10 Suppl):S12-9. [PMID: 21958918] http://dx.doi.org/10.1016/j.apmr.2011.04.025

95. Cella D, Nowinski C, Peterman A, Victorson D, Miller D, Lai JS, Moy C. The Neurology Quality of Life Measurement Initiative. Arch Phys Med Rehabil. 2011;92(10 Suppl):S28-36. [PMID: 21958920] http://dx.doi.org/10.1016/j.apmr.2011.01.025

96. Tulsky DS, Kisala PA, Victorson D, Tate D, Heinemann AW, Amtmann D, Cella D. Developing a patient-reported outcomes measure for spinal cord injury. Arch Phys Med Rehabil. 2011;92(10 Suppl):S44-51. [PMID: 21958922] http://dx.doi.org/10.1016/j.apmr.2011.04.024

97. Slavin MD, Kisala PA, Jette AM, Tulsky DS. Developing a contemporary functional outcomes measure for spinal cord injury research. Spinal Cord. 2010;48(3):262-67. [PMID: 19841635] http://dx.doi.org/10.1038/sc.2009.131

98. Atkinson D, Atkinson K, Kern M, Hale J, Feltz M, Graves DE. Reliability of the thoracic-lumbar control scale in spinal cord injury research. Arch Phys Med Rehabil. 2008: 89(10):e1. http://dx.doi.org/10.1016/j.apmr.2008.08.065

99. Marino RJ, Barros T, Biering-Sorensen F, Burns SP, Donovan WH, Graves DE, Haak M, Hudson LM, Priebe MM; ASIA Neurological Standards Committee 2002. International standards for neurological classification of spinal cord injury. J Spinal Cord Med. 2003;26 Suppl 1: S50-S56. [PMID: 16296564]
100. Marino RJ, Graves DE. Metric Properties of the ASIA motor score: Subscales improve correlation with functional activities. Arch Phys Med Rehabil. 2004;85(11): 1804-10. [PMID: 15520975] http://dx.doi.org/10.1016/j.apmr.2004.04.026

101. Stark S, Hollingsworth HH, Morgan KA, Gray DB. Development of a measure of receptivity of the physical environment. Disabil Rehabil. 2007;29(2):123-37. [PMID: 17364763] http://dx.doi.org/10.1080/09638280600731631

102. Gray DB, Hollingsworth HH, Stark S, Morgan KA. A subjective measure of environmental facilitators and barriers to participation for people with mobility limitations. Disabil Rehabil. 2008;30(6):434-57. [PMID: 17943511] http://dx.doi.org/10.1080/09638280701625377

103. Outcomes following traumatic spinal cord injury: A clinical practice guideline for health care professionals. Washington (DC): Paralyzed Veterans of America; 1999.

Submitted for publication June 2, 2010. Accepted in revised form February 1, 2011.

This article and any supplementary material should be cited as follows:

Ullrich PM, Spungen AM, Atkinson D, Bombardier CH, Chen Y, Erosa NA, Groer S, Ottomanelli L, Tulsky DS. Activity and participation after spinal cord injury: Stateof-the-art report. J Rehabil Res Dev. 2012;49(1):155-74. http://dx.doi.org/10.1682/JRRD.2010.06.0108

ResearcherID: Philip M. Ullrich, PhD: H-1758-2011

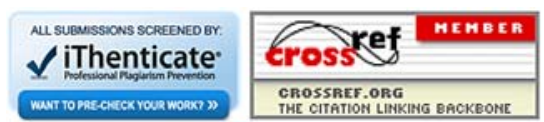


